Section Editors

David C. Spencer, MD

Steven Karceski, MD

Kathleen A. Smyth, PhD

\title{
Do enough women and minorities take part in drug studies for neurologic diseases?
}

WHY DOES IT MATTER IF WOMEN AND MINORITIES TAKE PART IN DRUG STUDIES FOR NEUROLOGIC DISEASES? Women and members of some minority groups are more likely than other Americans to have a stroke. Minorities are often more likely to have other neurologic diseases. This makes it important for women and minorities to take part in research that tests new drugs for stroke or other neurologic diseases. If there are not enough women and minorities in these drug studies, we will not know whether or not the study results can be applied to them. We also will not be able to decide whether the effects of the drug are the same in women and minorities as they are in other participants. In the past, the number of women and minorities taking part in drug studies has been very low. This has been changing recently, but in many drug studies, their participation is still too low. In their article in this issue of Neurology ${ }^{\circledR}$ (2011;76:354-360), Dr. Burke and his colleagues report how much progress has been made in involving women and certain minority groups in drug studies for neurologic conditions.

WHAT WAS LEARNED FROM THIS STUDY? Dr. Burke and his colleagues looked at participation by women, African Americans, and Hispanic Americans in the major drug studies funded by the National Institute of Neurological Disorders and Stroke (NINDS). The NINDS is the main source of federal funding for drug studies in neurologic diseases. They looked at all major studies completed between January 1977 and October 2009. They wanted to see whether reports about the studies mentioned how many women and minorities took part, and whether enough women and minorities were included. To see if there was change over time, they compared the studies completed before January 1995 (period 1) with those completed after that date (period 2). They chose these 2 periods because in 1995, the NIH made special efforts to encourage reporting of whether women and minorities took part in studies and to get more women and minorities into studies.

The authors looked at 56 studies. All of them reported on whether women took part. However, no more than $50 \%$ of the studies reported whether African Americans were included and less than $40 \%$ reported on whether Hispanic Americans were included. The rates of reporting did not change between period 1 and period 2. In studies where useful data were reported, the percent of women in drug studies went up from $37 \%$ to $43 \%$ between the 2 periods, and the percent of African Americans in the studies went up from $12 \%$ to $19 \%$. However, the percent of Hispanic Americans in the studies went down from $7 \%$ to $5 \%$.

WHAT DO THE STUDY FINDINGS MEAN FOR YOU? Women should find the results somewhat encouraging. Drug studies in neurologic conditions are regularly reporting whether women took part. The percent of women in studies has been increasing. This means that the results of more studies will apply to both women and men, and that more studies will be able to show whether the drug effects are the same for men and women. African Americans can also be encouraged by the fact that their participation in neurologic drug studies has been increasing. Still, many studies are not reporting whether or not African Americans took part, so we do not know whether the results of these studies apply to African Americans or not. Hispanic Americans have special cause for concern. Less than half of the examined studies reported whether Hispanic Americans were included. And although Hispanic Americans currently make up about $15 \%$ of the US population, their rate of participation neurologic drug studies is well below this level, and has decreased over time.

\section{WHAT CAN BE DONE TO IMPROVE THIS SITUATION?}

Researchers studying drugs for neurologic conditions need to recognize that their studies have not included enough Hispanic Americans, and that they need to improve outreach to this group. They also need to continue working to include enough women and African Americans in their studies so that these numbers do not drop. At the same time, women, African Americans, and especially Hispanic Americans need to be willing to consider taking part in drug studies when they are given the opportunity. Journals that publish findings from drug studies should insist that authors report the gender, race, and ethnicity of study participants. This way, health care providers who read these reports will know what groups the studies' findings apply to. 
Section Editors

David C. Spencer, MD

Steven Karceski, MD

\section{About clinical trials}

WHAT IS A CLINICAL TRIAL? A clinical trial is a research study that tests how people respond to a new drug or other health-related treatment. The goal is to see whether a new treatment is safe and effective. Clinical trials are usually done in phases. Phase I trials test a treatment in less than 100 people. This is done to see if the treatment is safe and to identify its side effects. Phase II trials study the treatment in several hundred people to see if it is effective. Safety and side effects are also measured again. Phase III trials are much larger studies with up to1,000 people or more. They gather more evidence about treatment effectiveness, safety, and side effects. Results are used to develop directions for health care providers about proper use of the treatment.

WHAT IS IT LIKE TO BE IN A CLINICAL TRIAL? There are many types of clinical trials. Clinical trials follow a protocol-a detailed description of how the study should be done. All trials involve some type of testing at the start and end of the trial so researchers can tell how safe and effective the treatment is. All trials also have rules for who can participate. Often, only people with a certain disease can join. A person's age or other characteristics or experiences might also affect whether he or she can participate. The goal is to include people in the study who can receive the treatment safely and benefit from it. In most clinical trials, "random assignment" is used. This procedure-similar to a coin toss-is done to select people who will receive the new treatment and those who will not. Those who do not get selected to receive the study treatment might receive a treatment that is already in use or they might receive a placebo. A placebo is something that looks the same as the treatment being studied, but does not have any treatment effect. Researchers use random assignment because it is a very good way to know whether any changes that take place in participants during the study are due to the new treatment.

WHAT ARE SOME PROS AND CONS OF BEING IN A CLINICAL TRIAL? Pros. Clinical trials participants get access to new treatments before they become widely available. There is a chance that re- ceiving the new treatment will be helpful. Participants can get useful information about their own health from the health care team in charge of the trial. Even if there is no personal gain, it can be very satisfying to help medical researchers discover new knowledge that might benefit large numbers of people in the future.

Cons. People who join clinical trials may receive a placebo instead of the new treatment. If they do receive the new treatment, they may not benefit from it. They could also have side effects from the new treatment, which could be severe or even lifethreatening. Some studies require large time commitments over long periods, which can be tiring or interfere with daily life.

SHOULD YOU PARTICIPATE IN A CLINICAL TRIAL? We need clinical trials to discover safe and effective medical treatments. Trials cannot be done unless people volunteer for them. To carefully evaluate a single new treatment, hundreds of volunteers are usually needed. Many thousands of volunteers are needed now to evaluate all promising new treatments on the horizon. Studies need volunteers from across the population, including women and minorities. While the need is great, you should get the answers to many questions before deciding to participate. These include the following: What is the purpose of the study? What kinds of tests and treatments will I experience? What are the possible benefits and side effects of the tests and treatments? How much time and effort will the trial require? Will there be any cost? Will I receive any payment? Will I be given the results of the trial at the end of the study? A properly run clinical trial will answer all these questions and more.

\section{FOR MORE INFORMATION}

clinicaltrials.gov

http://clinicaltrials.gov/ct2/home

Medlineplus: clinical trials

http://www.nlm.nih.gov/medlineplus/clinicaltrials.html

US Food and Drug Administration

http://www.fda.gov/forconsumers/byaudiencelforpatientadvocates/ participatinginclinicaltrials/default.htm 


\section{Neurology}

\section{Do enough women and minorities take part in drug studies for neurologic diseases? \\ Kathleen A. Smyth \\ Neurology 2011;76;e16-e17 \\ DOI 10.1212/WNL.0b013e31820a0d90}

\section{This information is current as of January 24, 2011}

\author{
Updated Information \& \\ Services
}

Subspecialty Collections

Permissions \& Licensing

Reprints including high resolution figures, can be found at:

http://n.neurology.org/content/76/4/e16.full

This article, along with others on similar topics, appears in the following collection(s):

All Genetics

http://n.neurology.org/cgi/collection/all_genetics

Information about reproducing this article in parts (figures,tables) or in its entirety can be found online at:

http://www.neurology.org/about/about_the_journal\#permissions

Information about ordering reprints can be found online:

http://n.neurology.org/subscribers/advertise

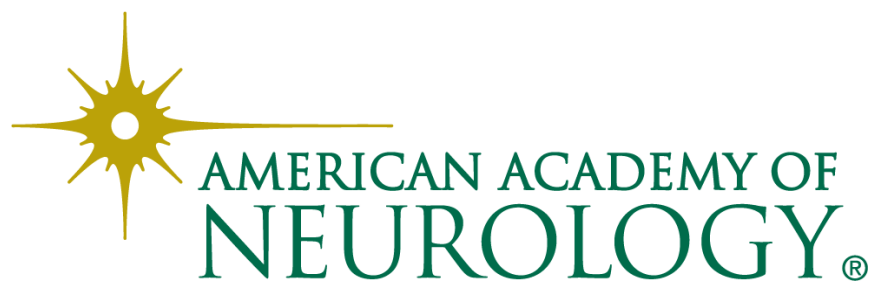

